\title{
Pengembangan Platform Pembelajaran Elektronik Untuk Mendukung Industri Kreatif (Creative E-Learning) Menggunakan Framework Open Source
}

\author{
Yusuf Yudhistira ${ }^{1}$, Mukrodin $^{2}$, Fuaida Nabyla ${ }^{3}$ \\ email: ${ }^{1}$ yudhis96@yahoo.com, ${ }^{2}$ mukrodins@gmail.com, ${ }^{3}$ nabilafuaida@gmail.com \\ ${ }_{1,2,3}$ Fakultas Sains \& Teknologi, Universitas Peradaban \\ Jl. Raya Pagojengan KM 03 Paguyangan Brebes 52276 Jawa Tengah
}

\begin{abstract}
Abstrak
Tujuan umum dari penelitian ini yaitu menghasilkan suatu model dan rancangan platform pembelajaran elektronik (e-learning platform) yang dapat digunakan oleh semua kalangan. Tujuan khusus pada penelitian ini adalah menggunakan platform pembelajaran tersebut untuk meningkatkan proses pembelajaran di bidang industri kreatif (creative e-learning platform). Pengembangan dilakukan di atas framework dan teknologi open source sehingga untuk mengadopsi platform pembelajaran kreatif ini tidak dibutuhkan biaya lisensi yang mahal. Sifat pengembangan yang open-source juga memudahkan pengembangan lebih lanjut tanpa melanggar hak cipta. Pengembangan tersebut memungkinkan juga kustomisasi pada platform pembelajaran untuk disesuaikan dengan situasi dan kondisi dari pengguna. Universitas Peradaban merupakan perguruan tinggi baru, memiliki potensi untuk berkembang terutama dalam penelitian di bidang TIK (Teknik Informatika dan Komputer). Terletak di daerah kabupaten/perkotaan kecil dengan posisi yang strategis, Universitas Peradaban dapat menjadi pusat pengembangan riset terpadu yang menjadi basis untuk pemerataan pendidikan dan pembangunan sumber daya manusia agar tidak terpusat pada kota-kota besar. Penelitian ini akan menggunakan metode pengembangan perangkat lunak berbasis objek dengan metodologi Unified Process (UP) dan pemodelan menggunakan Unified Modelling Language (UML). Menurut Jim Arlow dan Ila Neustadt [1], UP dan UML merupakan pengembangan perangkat lunak terkini yang tidak memisahkan antara data dan proses, bersifat iteratif dan inkremental, serta berfokus pada arsitektur.
\end{abstract}

Kata kunci : e-learning, platform, open source, unified process

\section{Pendahuluan}

Perkembangan teknologi informasi dan komunikasi (TIK) yang pesat belakangan ini, telah menghadirkan teknik pembelajaran baru, yaitu pembelajaran elektronik (e-learning). Tingkat adopsi peralatan teknologi informasi yang semakin luas dan merata, serta kapasitas jaring komunikasi yang semakin besar, memungkinkan dilaksanakannya pembelajaran elektronik.

Akan tetapi, peningkatan infrastruktur TIK tidak dibarengi oleh pengembangan platform pembelajaran elektronik dengan baik. Terutama platform pembelajaran elektronik yang dikembangkan di atas framework/teknologi open source. Hal ini menyebabkan tingkat adopsi pembelajaran elektronik yang masih sangat rendah di Indonesia pada umumnya, terutama di daerah kabupaten/kota kecil. Ada beberapa platform pembelajaran elektronik yang dikembangkan oleh pengembang di luar negeri, namun karena prosedur operasi standar tidak sesuai dengan kondisi di Indonesia, maka platform tersebut tidak dapat digunakan.

Hal lain yang menyebabkan minimnya adopsi platform pembelajaran elektronik yaitu kurang dukungan dari stakeholder yang berkepentingan dengan proses pembelajaran secara elektronik. Stakeholder di sini adalah pemerintah, pimpinan institusi, pengajar, maupun peserta didik. Pemerintah dan pimpinan kurang memberi insentif yang merangsang pengajar merancang bahan ajar dan teknik pembelajaran elektronik.

Namun demikian, situasi pandemi COVID-19 yang menghantui masyarakat di seluruh dunia, pada khususnya di Indonesia, telah memaksa perubahan cara berinteraksi sesama manusia dengan masif. Tidak diperkenankannya kerumunan atau berkumpulnya orang-orang dalam jumlah banyak di satu tempat telah menyebabkan pola pembelajan, dari sebelumnya secara tatap muka (offline/luring) menjadi secara virtual (online/daring). Fenomena berubahnya pola interaksi yang bersifat masif dan dalam jangka waktu yang singkat menyebabkan kegagapan pada skala yang tidak diperkirakan sebelumnya.

Perubahan-perubahan dalam menyikapi pandemi COVID-19 tersebut juga menyebabkan penggunaan infrastruktur jaringan internet sebagai pondasi untuk 
menyokong kegiatan daring menjadi overkapasitas. Selain itu, perangkat lunak (software) sebagai suprastruktur maupun sumber daya manusia (brainware) yang tidak siap juga menyebabkan kegagapan lebih lanjut.

Oleh karena itu, diperlukan platformplatform pembelajaran elektronik yang bisa mendukung pembelajaran secara daring dengan lebih efisien, efektif, mudah digunakan, sesuai dengan kondisi pembelajaran, dan berbiaya rendah ketika instalasi, operasional, sampai dengan pemeliharaan.

Permasalahan-permasalahan tersebut akan coba diperbaiki oleh platform pembelajaran elektronik yang akan dikembangkan, yaitu: (1) mengembangkan platform pembelajaran elektronik yang sesuai dengan kebutuhan pengguna, meningkatkan adopsi pembelajaran elektronik di lembaga formal maupun non-formal di daerah sekitar Universitas Peradaban, (3) menjadikan Universitas Peradaban sebagai universitas riset di bidang pembelajaran elektronik, (4) menggunakan metodologi Unified Process (UP) dan Unified Modelling Language (UML) yang merupakan metodologi pengembangan perangkat lunak yang lebih intuitif dibanding metodologi lain.

Platform pembelajaran elektronik yang akan dikembangkan memiliki kebaruan dan terobosan teknologi, yaitu: (1) menggunakan framework open source agar siapa saja dapat berkontribusi mengembangkan platform pembelajaran elektronik dengan bebas tanpa khawatir dengan hak kekayaan intelektual, (2) dalam proses pengembangan melibatkan stakeholder yang berkepentingan dengan platform pembelajaran elektronik ini.

\section{Metode Penelitian}

Pembelajaran elektronik (e-Learning) adalah proses pembelajaran yang dibantu oleh teknologi informasi dan komunikasi (TIK). Menurut Yang, Dong [2], ada tiga jenis pembelajaran, yaitu pembelajaran tradisional (traditional learning), pembelajaran elektronik (e-learning), dan pembelajaran campuran (blended-learning). Kelebihan utama dari pembelajaran tradisional yaitu adanya interaksi tatap muka antara pengajar dan murid. Sedangkan kelebihan utama dari pembelajaran elektronik adalah memungkinkan murid untuk belajar kapan saja dan di mana saja.
Pembelajaran campuran berusaha menggabung kelebihan dari keduanya.

Pina, Lowell, Harris [3] menyebutkan agar pembelajaran elektronik berlangsung dengan baik ada 2 faktor yang harus dipenuhi. Pertama, infrastruktur yang memadai. Kedua, leadership pada penyelenggara pembelajaran elektronik. Faktor pertama memastikan bahwa perangkat keras, perangkat lunak, dan jaringan mampu untuk mengakomodasi platform pembelajaran elektonik, apalagi jika platform tersebut memiliki fitur interaktif dan multimedia, serta diakses oleh banyak pengguna. Faktor kedua memastikan bahwa stakeholder yang berkepentingan (terutama unsur pemimpin) memiliki arah kebijakan yang jelas terhadap penggunaan platform pembelajaran elektronik di institusi yang dipimpinnya, misal dengan memberi insentif khusus bagi pengajar yang menggunakan platform pembelajaran elektronik.

Pengembangan sistem informasi (SI) merupakan jenis pengembangan yang bersifat tidak intuitif. Dibutuhkan abstraksi yang lebih kompleks dibandingkan dengan pengembangan yang lain, misal pengembangan di bidang konstruksi bangunan. Karena sifatnya yang tidak intuitif tersebut, banyak proyek pengembangan SI yang gagal [4]. Untuk mengantisipasi kegagalan pengembangan SI, digunakanlah SDLC (systems development life cycle). Pada penerapannya, SDLC membutuhkan suatu metodologi. Unified Process (UP) merupakan salah satu metodologi penerapan SDLC [1].

Unified Process (UP) merupakan salah satu metodologi pengembangan sistem yang diperkenalkan oleh Three Amigos, yaitu tiga orang yang bergabung dan menyatukan metodologi pengembangan sistem yang mereka buat. Mereka adalah Booch, Rumbaugh, dan Jacobson. Metodologi tersebut membagi pengembangan perangkat lunak ke dalam 4 fase (Gambar 1) [4], yaitu fase persiapan (inception), elaborasi (elaboration), fase konstruksi (construction), fase transisi (transition). Masing-masing fase dibagi ke dalam 7 alur kerja teknik (engineering workflow) dan 3 alur kerja pendukung (supporting workflow). Alur kerja teknik antara lain: pemodelan bisnis (business modelling), keperluan (requirements), analisis (analysis), perancangan (design), implementasi (implementation), pengujian (test), dan penyebaran (deployment). Alur kerja 
pendukung antara lain: manajemen konfigurasi dan perubahan, manajemen proyek, dan analisis lingkungan [4].

Unified Modelling Language (UML) adalah bahasa pemodelan yang digunakan untuk memodelkan pengembangan perangkat lunak. UML merupakan rangkaian notasi yang digunakan di dalam UP. Namun secara de facto, UML sudah menjadi standar pemodelan walaupun metodologi pengembangan yang digunakan bukan UP [5].

Untuk mengembangkan SI secara baik, di samping membutuhkan sebuah metodologi yang sudah terbukti berhasil, diperlukan juga sebuah framework. Tujuan utama dari penggunaan framework adalah untuk memudahkan implementasi SI. Penyebab munculnya framework pengembangan diakibatkan karena ada banyak bahasa pemrograman yang dapat digunakan dan disaling-gabungkan. Framework mencegah pengembang membuat ulang (reinventing the wheels) metode-metode atau prosedurprosedur yang sering digunakan.

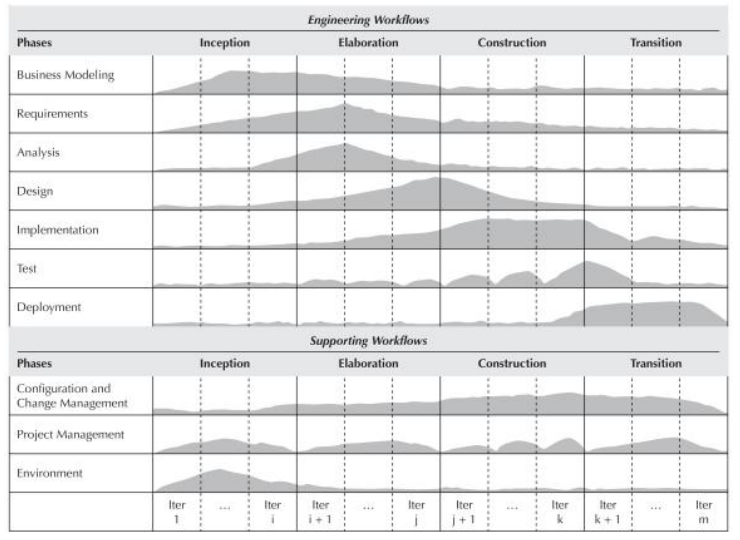

Gambar 1 Fase dan alur kerja pada Metodologi Unified Process (UP)

Menurut Safronov, Winesett [6], keuntungan yang diperoleh dengan penerapan framework pengembangan, yaitu: (1) Mencegah perulangan di antara proyek-proyek. (2) Memanfaatkan desain responsif agar website mampu beradaptasi pada ukuran layar yang bermacam-macam . Misal: smartphone, tablet, desktop, dsb. (3) Memastikan konsistensi pada rancangan dan kode pemrograman di antara proyek-proyek dan di antara pengembang-pengembang.

Mempercepat dan mempermudah pengembangan sistem informasi baru. (5) Menjamin tingkat keamanan sistem informasi. (6) Memastikan kompatibilitas antar-peramban (browser). (7) Meningkatkan kolaborasi antar pengembang agar bekerja dengan cepat dan harmonis. (8) Memudahkan pengembang baru untuk beradaptasi dengan cepat.

Mengingat perannya yang sangat vital tersebut, penerapan framework sudah bersifat wajib. Namun demikian, penerapan framework juga memiliki kekurangan [7], diantaranya: (a) Menyebabkan server bekerja lebih berat, karena adanya server overhead. Dapat diatasi dengan teknik caching. (b) Membutuhkan waktu untuk mempelajari cara kerja framework, karena banyak bagian2 dari framework tidak dibuat oleh tim pengembang.

Terdapat satu gerakan komunitas terbuka (open community) di dunia pengembangan perangkat lunak. Gerakan tersebut menelurkan perangkat lunak yang bersifat open source. Misi utama dari gerakan tersebut adalah untuk menggratiskan biaya lisensi bagi pengguna yang ingin menggunakan perangkat lunak open source, sehingga pengguna dapat mengimplementasikan SI secara lebih murah. Walaupun biaya lisensinya gratis, bukan berarti perangkat lunak open source dibuat asal-asalan dan tidak memiliki fitur-fitur yang mumpuni. Bahkan perangkat lunak open source selalu menempati urutan teratas jumlah penggunanya. Tentunya karena perangkat lunak tersebut gratis dan memiliki fitur yang sesuai dengan kebutuhan pengguna.

Dengan adanya gerakan open community dengan perangkat lunak open source-nya, adopsi teknologi informasi dan komunikasi (TIK) terbukti mampu menjangkau segala lapisan masyarakat. Sehingga pemerataan penggunaan TIK dapat dicapai dengan maksimal. Pada akhirnya, seluruh masyarakat dapat menikmati perkembangan ekonomi dan peningkatan taraf hidup.

Penelitian ini menggunakan teknik pengumpulan data dengan cara melakukan studi banding dan survei pada lembaga pendidikan formal seperti universitas dan sekolah sebagai benchmark penerapan pembelajaran elektronik yang sudah berjalan. Dari kegiatan tersebut, peneliti akan mendapat keberhasilan dan kendala-kendala penerapan pembelajaran elektronik. Data tersebut akan digunakan sebagai basis untuk melakukan perbaikan-perbaikan pada analisis dan perancangan platform pembelajaran elektronik. Teknik pengumpulan data berikutnya adalah dengan menyebarkan kuesioner untuk 
menangkap pengetahuan responden tentang adanya e-learning (pembelajaran elektronik) dan keefektifannya dalam pelaksanaan pembelajaran. Melalui olahan data kuesioner tersebut, bentuk platform e-learning akan dikembangkan, sehingga sesuai dengan kebutuhan pengguna.

Peneliti juga akan menggunakan teknik joint application design (JAD) untuk menangkap keinginan pengguna secara lebih komprehensif. Teknik JAD merupakan teknik perancangan aplikasi secara bersama-sama yang melibatkan tim pengembang dan seluruh stakeholder yang berkepentingan pada platform yang dikembangkan [8]. Teknik JAD terbukti efektif mengekstraksi keinginan pengguna terhadap fitur-fitur pada SI yang akan dikembangkan [1].

Pada penelitian ini, metodologi pengembangan yang digunakan adalah metodologi Unified Process (UP) dengan menggunakan bahasa pemodelan Unified Modelling Language (UML). Menurut Dennis, Wixom, Tegarden [4], metodologi UP terdiri atas 3 fase, yakni: fase permulaan (inception), elaborasi (elaboration), konstruksi (construction), transisi (transition). Yang perlu juga digarisbawahi dari metodologi UP yakni sifatnya yang inkremental dan iteratif.

\section{Hasil dan Pembahasan}

Pengembangan platform menggunakan metodologi Unified Process (UP) melalui beberapa fase dan alur kerja yang menghasilkan model-model dan rancanganrancangan yang akan digunakan sebagai blueprint (cetak biru) dalam implementasi dan penyebaran sistem.

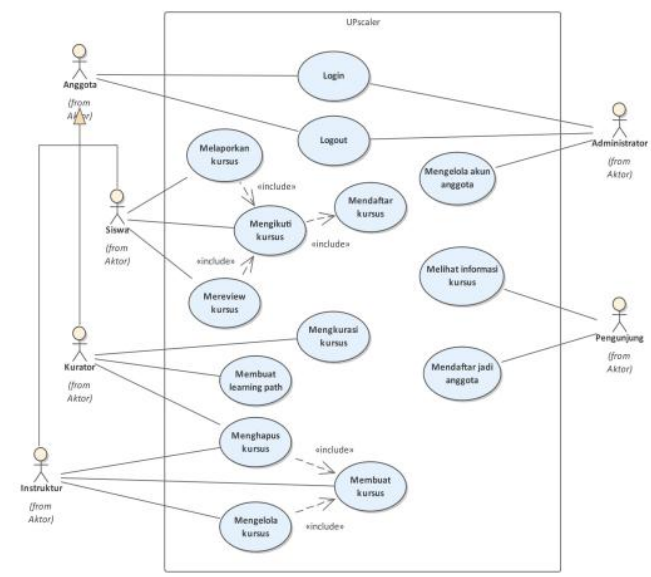

Gambar 2 Diagram Use-Case dari UPscaler ${ }^{\mathrm{TM}}$
Dari alur kerja Pemodelan Bisnis dan Analisis Keperluan didapatkan definisi keperluan UPscaler ${ }^{\mathrm{TM}}$ seperti pada TABEL 1 dan TABEL 2. Proses pembelajaran pada UPscaler $^{\mathrm{TM}}$ disebut dengan kursus. Keperluan Fungsional digambarkan dengan Diagram UseCase (Gambar 2). Terdapat 6 Aktor pada Upscaler $^{\mathrm{TM}}$, yaitu: (1) Administrator, (2) Pengunjung, (3) Anggota yang terspesialisasi menjadi (4) Siswa, (5) Instruktur, dan (6) Kurator. Masing-masing Aktor memiliki peran yang dijelaskan pada TABEL 2.

TABEL 1

KEPERLUAN NON-FUNGSIONAL

\begin{tabular}{|c|c|}
\hline \multicolumn{2}{|c|}{ 1. Keperluan Operasional } \\
\hline 1.1 & $\begin{array}{l}\text { Sistem berbasis web, dapat diakses } \\
\text { menggunakan peramban (browser) baik } \\
\text { pada desktop maupun pada smartphone. }\end{array}$ \\
\hline 1.2 & $\begin{array}{l}\text { Sistem mampu beradaptasi dengan ukuran } \\
\text { dan resolusi layar yang berbeda-beda. }\end{array}$ \\
\hline 1.3 & $\begin{array}{l}\text { Sistem dapat melakukan backup pada } \\
\text { akhir hari. }\end{array}$ \\
\hline \multicolumn{2}{|c|}{ 2. Keperluan Kinerja } \\
\hline 2.1 & $\begin{array}{l}\text { Sistem mampu menampilkan } \text { materi } \\
\text { pembelajaran kurang dari } 10 \text { detik. }\end{array}$ \\
\hline 2.2 & $\begin{array}{l}\text { Sistem mampu memproses seluruh } \\
\text { transaksi pengguna (registrasi, rating, } \\
\text { penilaian, dsb.) kurang dari } 5 \text { detik. }\end{array}$ \\
\hline \multicolumn{2}{|c|}{ 3. Keperluan Keamanan } \\
\hline 3.1 & $\begin{array}{l}\text { Sistem dapat membedakan role (peran) } \\
\text { dan tugas setiap pengguna. }\end{array}$ \\
\hline 3.2 & $\begin{array}{l}\text { Sistem mampu menjaga menangkal } \\
\text { serangan cyber. }\end{array}$ \\
\hline \multicolumn{2}{|c|}{ 4. Keperluan Budaya dan Politik } \\
\hline 4.1 & $\begin{array}{l}\text { Sistem dapat menghapus materi kursus } \\
\text { yang bertentangan dengan Pancasila \& } \\
\text { UUD 1945, melanggar HAM dan SARA. }\end{array}$ \\
\hline
\end{tabular}

TABEL 2

KEPERLUAN FUNGSIONAL

\begin{tabular}{ll}
\hline 1. Fungsi Anggota \\
\hline 1.1 & Anggota melakukan login \\
1.2 & Anggota melakukan logout \\
\hline 2. Fungsi Pengunjung \\
\hline $2.1 \quad$ Pengunjung melihat informasi kursus \\
2.2 & Pengunjung mendaftar menjadi anggota \\
\hline 3. Fungsi & Administrator \\
\hline 3.1 & Administrator mengelola akun anggota \\
\hline 4. Fungsi & Siswa \\
\hline 4.1 & Siswa mendaftar kursus \\
4.2 & Siswa mengikuti kursus \\
4.3 & Siswa menilai (rate \& review) kursus \\
4.4 & Siswa melaporkan kursus \\
\hline 5. Fungsi Instruktur \\
\hline 5.1 & Instruktur membuat kursus \\
5.2 & Instruktur menghapus kursus \\
5.3 & Instruktur mengelola kursus \\
\hline 6. Fungsi & Kurator \\
\hline 6.1 & Kurator mengkurasi kursus \\
6.2 & Kurator membuat learning path \\
6.3 & Kurator menghapus kursus \\
\hline
\end{tabular}


Untuk mendukung fungsionalitas, UPscaler $^{\mathrm{TM}}$ dirancang mampu menangani 3 jenis kursus, yaitu: (1) Kursus mandiri bebas (self-paced no time limit), yakni model pembelajaran mandiri dengan waktu yang tidak dibatasi, bisa ada evaluasi atau tanpa evaluasi. (2) Kursus mandiri terbatas (selfpaced with limited time), yakni model pembelajaran mandiri dengan waktu yang dibatasi. Terdapat evaluasi untuk menentukan pemahaman siswa. (3) Kursus dengan pembinaan terjadwal (scheduled coaching), yakni model pembelajaran dengan pendampingan/ pertemuan. Terdapat jadwal yang harus dipenuhi per pertemuan. Instruktur menentukan jumlah pertemuan dan materinya. Terdapat evaluasi untuk memantau proses pembelajaran siswa. Evaluasi dapat berupa kombinasi kuis, tugas (assignment), tes pertengahan (mid-term), dan/atau tes akhir (final-term).

TABEL 3

JENIS KURSUS PADA UPscaler ${ }^{\mathrm{TM}}$

\begin{tabular}{|c|c|c|c|}
\hline Jenis Kursus & $\frac{\vec{E}}{\frac{\pi}{\pi}}$ & $\begin{array}{l}\overline{\vec{z}} \\
\stackrel{\Xi}{\Xi} \\
\vec{\pi} \\
\vec{\omega}\end{array}$ & $\begin{array}{l}\frac{\pi}{0} \\
\frac{\pi}{0} \\
2\end{array}$ \\
\hline Mandiri bebas & - & o & - \\
\hline Mandiri terbatas & $\sqrt{ }$ & $\sqrt{ }$ & o \\
\hline Pembinaan terjadwal & $\sqrt{ }$ & $\sqrt{ }$ & $\sqrt{ }$ \\
\hline
\end{tabular}

Selain itu terdapat 4 kriteria tingkat kesulitan kursus, yaitu: dasar, pemula, menengah, dan mahir. Kurator dapat membuat learning pathway (jalur pembelajaran) dengan menghimpun kursus-kursus yang berkaitan dalam satu urutan kursus agar siswa bisa mempelajarinya dengan urutan yang berkembang dari tingkat dasar sampai tingkat mahir. Siswa juga dapat memberikan rating kursus dengan memberi bintang 1-5 dan memberikan alasannya. Lebih lanjut siswa bisa melaporkan kursus yang sekiranya isinya menyimpang, misal melanggar HAM, SARA, dan kesusilaan; berpotensi menimbulkan perpecahan dan adu domba; atau alasan lainnya.

UPscaler $^{\mathrm{TM}}$ dirancang mampu mengakomodasi beberapa metode dalam membekali kompetensi siswa, yaitu [9]: (1) problem-based learning, (2) project-based learning, (3) contextual learning, (4) experiential learning, (5) collaborative learning, (6) cooperative learning, (7) inquiry- based learning, (8) flipped classroom, (9) gamification. TABEL 4 menggambarkan kesesuain metode pembelajaran dengan jenis kursus. Terlihat bahwa UPscaler ${ }^{\mathrm{TM}}$ tidak dapat mengakomodasi cara pembelajaran gamification.

TABEL 4

METODE PEMBELAJARAN vs JENIS KURSUS PADA UPscaler ${ }^{\mathrm{TM}}$

\begin{tabular}{|c|c|c|c|}
\hline \multirow[b]{2}{*}{ Metode Pembelajaran } & \multicolumn{3}{|c|}{ Jenis Kursus } \\
\hline & 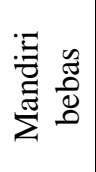 & 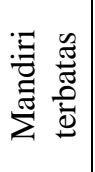 & 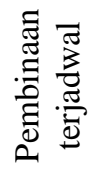 \\
\hline Problem-based learning & $\sqrt{ }$ & $\sqrt{ }$ & $\sqrt{ }$ \\
\hline Project-based learning & $\sqrt{ }$ & $\sqrt{ }$ & $\sqrt{ }$ \\
\hline Contextual learning & - & $\sqrt{ }$ & $\sqrt{ }$ \\
\hline Experiential learning & $\sqrt{ }$ & $\sqrt{ }$ & $\sqrt{ }$ \\
\hline Collaborative learning & - & - & $\sqrt{ }$ \\
\hline Cooperative learning & - & - & $\sqrt{ }$ \\
\hline Inquiry-based learning & - & $\sqrt{ }$ & $\sqrt{ }$ \\
\hline Flipped classroom & - & - & $\sqrt{ }$ \\
\hline Gamification & - & - & - \\
\hline
\end{tabular}

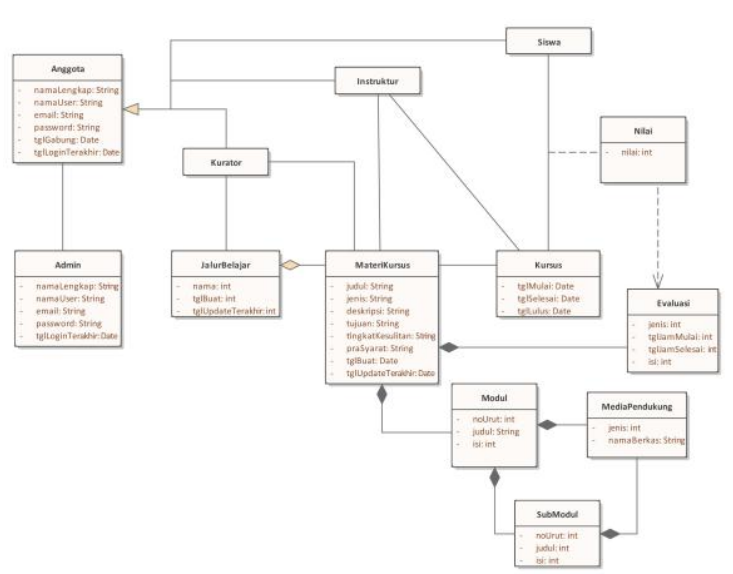

Gambar 3 Diagram Kelas dari UPscaler ${ }^{\mathrm{TM}}$

Setelah Model Fungsional dibuat, kemudian Model Struktural dibangun dengan melakukan analisis pada Model Fungsional dengan menentukan kandidat-kandidat kelas dan menuangkannya ke dalam Kartu CRC (Class Responsibilily Collaboratrion). Selanjutnya Kartu CRC tersebut dimainperankan (role-playing) untuk mengidentifikasikan atribut dan method dan menetapkan kelas dari kandidat-kandidat kelas. Akhirnya didapat Model Struktural yang digambarkan dengan Diagram Kelas (Gambar $3)$.

Terdapat 13 kelas yang ditetapkan, yaitu: (1) Anggota, (2) Siswa, (3) Instruktur, (4) Kurator, (5) Admin, (6) JalurBelajar, (7) MateriKursus, (8) Kursus, (9) Modul, (10) 
SubModul, (11) MediaPendukung, (12) Evaluasi, dan (13) Nilai.

Rancangan Basisdata ditunjukkan dengan Diagram Entity-Relationship (Gambar 4). Terdapat 9 tabel utama pada basisdata UPscaler $^{\mathrm{TM}}$, yaitu: (1) pengguna, (2) kursus, (3) materi_kursus, (4) modul, (5) sub_modul, (6) evaluasi, (7) nilai, (8) jalur_belajar, (9) media_pendukung.

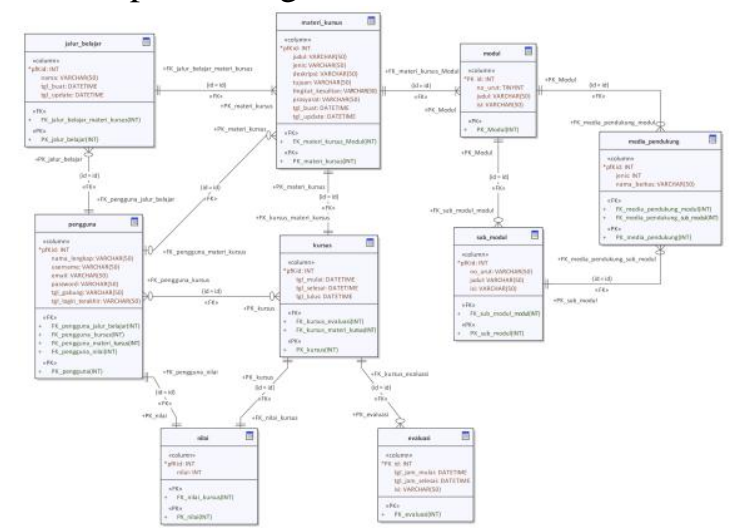

Gambar 4 Rancangan basisdata UPscaler ${ }^{\mathrm{IM}}$

\section{Kesimpulan}

UPscaler ${ }^{\mathrm{TM}}$ menjawab kebutuhan
platform pembelajaran elektronik yang
berbasis komunitas (community based),
terbuka (open access), transparan, kreatif,
terstruktur, dan terarah. Keistimewaan
UPscalerTM ada pada fleksibilitasnya yang
dapat menangani 3 jenis kursus dengan 8
variasi metode pembelajaran. Anggota dapat
dengan bebas mengakses materi maupun
memberikan materi, sehingga pada jangka
panjang UPscaler dapat menjadi gudang kursus
(courses repository). Transfer ilmu
pengetahuan yang difasilitasi oleh platform
pembelajaran seperti UPscaler ${ }^{\mathrm{TM}}$ dapat terjadi
dengan mudah.
UPscaler mudah dikembangkan lebih
lanjut karena dibangun dengan konsep open- source. Platform ini juga bisa disematkan dengan sistem yang sudah ada pada suatu lembaga, baik formal maupun non formal. Ke depan, pengembangan UPscaler dapat dilakukan lebih lanjut untuk meningkatkan fitur-fitur agar mampu menangani metodemetode pembelajaran terbaru.

\section{Daftar Pustaka}

[1] J. Arlow and I. Neustadt, UML 2 AND THE UNIFIED PROCESS 2nd Ed. Addison-Wesley, 2005.

[2] D. Yang, LEARNING PATH CONSTRUCTION IN E-LEARNING. Springer, 2017.

[3] Pina, Lowell, and Harris, LEADING AND MANAGING E-LEARNING. Springer.

[4] Dennis, Wixom, and Tegarden, SYSTEM ANALYSIS AND DESIGN - AN OBJECTORIENTED APPROACH WITH UML, 5th ed. Wiley, 2015.

[5] Pilone and Pitman, UML 2.0 IN A NUTSHELL. O'Reilly, 2005.

[6] Safronot and Winesett, WEB APPLICATION DEVELOPMENT WITH YII2 AND PHP. Packt Publishing, 2014.

[7] P. II, MASTERING YII. Packt Publishing, 2016.

[8] Rakhman, A., \& Rais, R. (2020). Analisa Pakan Burung Otomatis Menggunakan Arduino Berbasis Internet Of Things. Syntax Literate; Jurnal Ilmiah Indonesia, 5(5), 18-25.

[9] Whitten and Bentley, SYSTEM ANALYSIS AND DESIGN METHODS, 7th ed. McGraw-Hill Irwin, 2007.

[10] R. A. Sani, STRATEGI BELAJAR MENGAJAR, 1st ed. Rajawali Press, 2019. 